\title{
Analysis of 2014 Post UTME Score of Candidates in the University of Ibadan with Two Methods of Standard Setting to Set Cut Off Points
}

\author{
Babatunde Oladele ${ }^{1}$
}

\begin{tabular}{l} 
ARTICLE INFO \\
\hline Article History: \\
Received 03.03.2017 \\
Received in revised \\
form 09.05 .2017 \\
Accepted \\
Available online \\
01.07 .2017
\end{tabular}

\begin{abstract}
The aim of the current study is to analyse the 2014 Post UTME scores of candidates in the university of Ibadan towards the establishment of cut off using two methods of standard settings. Prospective candidates who seek admission to higher institution are often denied admission through the Post UTME exercise. There is no single recommended approach to standard setting and many methods exist. These include norm-referenced methods and the criterionreferenced methods. The Angoff method is the most widely used and researched criterion-referenced method of standard setting. Two different methods of standard setting were applied on the raw scores of 648 Post-UTME candidates in the University of Ibadan. One of these was the modified Angoff method and the other the norm-reference method of standard setting (mean minus $1 \mathrm{SD}$ ). The pass rates derived from the two methods were compared. The result revealed the pass rate with the norm-reference method was $85 \%(551 / 648)$ and that by the Angoff method was 50\% (340/648). The percentage agreement between Angoff method and norm-reference was found to be $54 \%$ with the Angolf modified method, whilst by the norm-reference method was $85 \%$. Thus, the two standardsetting methods used, produced significantly different outcomes. This was demonstrated by the different pass rates.
\end{abstract}

(C) 2017 IJERE. All rights reserved

Keywords:

Cut-Off Point, Post-UTME, Standard Setting.

\section{INTRODUCTION}

The admission processes and procedures in Nigeria Universities has changed since the introduction of Post Unified Matriculation Examination (Post -UTME) in 2005 with the aim of ensuring that quality prospective candiates are admitted into the country higher institution of learning. Post-UTME is an examination approved by the Federal Government of Nigeria for all uvniversities to conduct for candiates who have passed the Joint Admission Matriculation Board (JAMB) examination at a prescribed score between 180 and 200. University is regarded as the single and most important industry for the production of high-level manpower in Nigeria. Ume (1979) submitted that the aims of university education are to raise the intellectual tone of the society, cultivate the public mind, purify the national taste, supply the principles of popular aspirations and give enlargement and sobriety to ideas of the age. To strengthen these principles the stakeholders in Nigerian university education sector tend to guard jealously the integrity of the university and the quality of graduates produced (Olayemi \& Oyelekan, 2009).

The need to ensure only competent and qualified candidates are admitted into Nigerian Universities and cross-validate the scores of candidates in the Unified Tertiary Matriculation Examination (UTME) are the advances made to justify the introduction of Post Unified Tertiary Matriculation Examination (PostUTME) by NigerianUniversities (Ado, 2015). The excercise is now complex because many candidates who could not make the cut off point stipulated by the universities designed to get the quota of dmission approved by the regulatory body, the National Universities Commission. A cut off point is a point on a scale

${ }^{1}$ Corresponding e-mail: oladelebatunde@gmail.com 
that separate one performance standard from another. It serves as a yardstick or benchmark for making high stake decision for student performance. In order to distinguish between those who are competent to do the test and those who are not, trainers need to define the acceptable levels of competency as they relate to performance. The outcome of any assessment is determined by the standard-setting method used. Standard - setting is defined as "the process of deciding what is good enough" There is no single method of choice for standard setting and many methods exist. These include norm - reference methods and the criterion reference methods. Each standard- setting method has its advantages and disadvantages, and there is no gold standard. A criterion-referenced standard is generally preferred to a norm-referenced (fixed pass rate) or holistic.

It has been found that different methods of setting standards result in different standards and hence it is argued that the validity of a test is determined as much by the method used to set the standard, as by the test content itself. Downing SM, Tekian, and Yudkowsky (2006) argued that all standards are ultimately policy decisions and that 'there is no gold standard for a passing score. What is important is the process of setting the standard. The four important criteria that underpin the process of standard setting are that it is systematic, reproducible, absolute and unbiased. The specific score that is used as the cutoff is what separates those who pass a test from those who do not. It is this score that determines the consequences of taking the test. However, a line must be drawn somewhere to distinguish between those who possess enough knowledge to pass a test, to be considered further for education level, to be certified, or to be licensed. It is the specific score called the cutoff score that creates the two classes of people: those who pass and those who fail. There are many standard setting methods used to set cut scores. These methods are generally split into two types: a) question-centered approaches and b) participant-centered approaches.

Kane (1994) stated that the passing score is a point on the observed-score scale whereas the standard is a conceptual boundary on the true-score scale between acceptable and non-acceptable performance. Or in other words, a standard is the 'boundary between those who perform well enough and those who do not. Standards are generally classed as absolute (criterion based) or relative (norm based). An absolute standard determines the pass/fail outcome by how well a candidate performs and he/she is usually judged against an arbitrarily set external standard. Hence it is independent of the performance of the group. A relative standard on the other hand, compares how well the examinee has performed compared to others who took the test and hence the outcome (pass/fail) is dependent on the performance of the group.

The outcome of assessments is determined by the standard-setting method used. Cusimano (1996) defined standard - setting as "the process of deciding what is good enough". The most widely used and researched criterion reference method of standard setting is the Angoff method. In the Angoff method, a panel of judges examines each multiple-choice item or item on a checklist and estimates the probability that the "minimally competent" or "borderline" candidate would answer the item correctly. Then the scores are discussed in the group and consensus is reached if possible. This stage is avoided in the modified approach. Each judge's estimate scores on all items are added up and averaged and the test standard is the average of these means for all the judges. Each standard- setting method has its advantages and disadvantages, and there is no gold standard.

Amatareotubo (2006) describes how the federal government of Nigeria introduced the policy of Post-JAMB screening by universities in 2005, through the Minister of Education, Mrs. Chinwe Obaji. This policy made it mandatory for all tertiary institutions to screen candidates after their JAMB results and before giving admission. Candidates with a score of 200 and above would be shortlisted by JAMB and their names and scores sent to their universities of choice which would screen again using aptitude tests, oral interviews, or even another examination. Obaji asserts that some candidates scored 280 and above in JAMB but could not score 20 percent in the post-JAMB examination, believing that those students must have cheated on their JAMB examinations and could not pass the Post-JAMB examination because there was no way to cheat. Some students employ unethical means to pass JAMB on their first attempt, but find it difficult to scale through the hurdle of Post-Jamb. Oyedele (2008) quotes the University of Ado Ekiti Vice-Chancellor, Professor Dipo Kolawole, a well-known supporter of the Post-UME test, as saying that "in the past a student will score 289, automatically he comes in, but with the Post-UME now, you find that such a student is 
scoring a very poor mark. They cannot even write. If we desire sanitation of our educational system it does not make sense for anybody to be against the post-UME. If there are other built in mechanisms to purify the admission process it should be a welcome idea." Nigeria has a body that regulates educational qualifying examinations. Four prominent public examination bodies in Nigeria are the Joint Admission and Matriculation Board (JAMB), the National Business and Technical Examination Board (NABTEB), the National Examination Council (NECO), and the West African Examination Council (WAEC),

It is mandatory that candidates seeking admission to any of the university in Nigeria, whether federal, state, or private, take and pass the Joint Admission and Matriculation Board (JAMB) Examination before being considered for the Post-University Matriculation Examination screening, conducted by each university before the admission of these who qualify or pass. There are cut off points that will be used to determine the candidate who are qualified to be admitted. However, the Post-Jamb exercises are being conducted and coordinated by the University Admission Committee, who decides the cut-off point on which candidates are admitted to the institution of learning. The methods of standard settings employed by the Universities are unknown to the public. It is on this basis that the study used two method of standard setting to analysis the 2014 Post-UTME score of prospective candidates in the University of Ibadan to set cut off points.

Many candidates who prepared for Post-UTME in Nigeria are not aware of the methods of setting standards being adopted by the Universities of their choice to determine cut off point for admissions, but they only prepare for the examination. A lot of the candidate did not get admitted by the Universities because they failed to pass the institution Post-UTME and this could be as result of them not reaching the cut-off points established by the institution of learning Admission Committee. Because the outcome of assessments is determined by the standard-setting method used and because different methods of setting standards result in different standards, the choice and process of the method used is of utmost importance. The failure to meet the cut-off points might be as a result of the method adopted by the Admission Committee of Universities. This study therefore analyzed the 2014 Post-UTME scores of candidates with two methods of setting standards.

Aim of the present study is to determine and analyse the methods of standard setting being adopted by higher institution for the admission of candidates through Post-UTME. Within the framework of this general aim, answers to the following questions have been sought: 1. What is the agreement between the two standards when used to analyze the candidate scores in Post UTME? 2. What is the pass rates resulting from the application of the two standard setting methods on candidate scores in Post -UTME

\section{METHOD}

The study employed expo facto research design of the survey reasech type. This was employed, since the data involved in the study were collected from the source (University Website) without any manipulation involving the use of 2014 Post-UTME scores of candidates in the University of Ibadan. To test the supposed research questions of the proposed framework, the researcher used two method of setting standard, norm-reference method and modified Angolf method. The total population .Simple randon sampling was used to select six hundred and eighty four (648) candidates who choose courses in the Faculty of Education as sample for the study.

\section{Material}

Using the two different standard-setting methods, the norm-reference method and modified Angolf method. Two standards were determined. The two methods were compared by their pass rates. In the normreference method, the standard was determined by calculating the mean of the scores and standard deviation (SD). The standard was set as the adjusted mean minus 1.0 SD. For the modified Angolf method, the researcher assumed that the Admission Committee of the institution served as the panel of judges who participate in the standard-setting round. A consensus on the definition of a minimally acceptable cut-off point that is borderline candidate was reached.

\section{Data Analyses}


Statistical analysis was done using SPSS version 20 to analyse the frequency, percentages, mean and standard deviation of candidates' scores. The pass rates were calculated based on the pass rates scores set for each of the method.

Table 1: Gender Distribution of Candidates

\begin{tabular}{lll}
\hline Gender & Frequency & Percentage (\%) \\
\hline Male & 222 & 34.3 \\
Female & 426 & 66.7 \\
Total & $\mathbf{6 4 8}$ & $\mathbf{1 0 0}$ \\
\hline
\end{tabular}

Table 1 revealed that out of the six hundred and forty eight candidate who choose courses of study in education $34.3 \%$ were male and 66.7 were female. This indicates that the numbers of prospective female who are interested in becoming teachers and research fellow are more than their male counterpart.

Table 2: Score Distribution of Candidates

\begin{tabular}{|c|c|c|}
\hline Score & Frequency & Percentage (\%) \\
\hline 9 & 1 & .2 \\
\hline 16 & 1 & .2 \\
\hline 18 & 2 & .3 \\
\hline 19 & 1 & .2 \\
\hline 20 & 1 & .2 \\
\hline 21 & 1 & .2 \\
\hline 22 & 4 & .6 \\
\hline 23 & 2 & .3 \\
\hline 24 & 1 & .2 \\
\hline 25 & 4 & .6 \\
\hline 26 & 4 & .6 \\
\hline 27 & 1 & .2 \\
\hline 28 & 6 & .9 \\
\hline 29 & 1 & .2 \\
\hline 30 & 6 & .9 \\
\hline 31 & 4 & .6 \\
\hline 32 & 6 & .9 \\
\hline 33 & 7 & 1.1 \\
\hline 34 & 9 & 1.4 \\
\hline 35 & 5 & .8 \\
\hline 36 & 4 & .6 \\
\hline 37 & 11 & 1.7 \\
\hline 38 & 13 & 2.0 \\
\hline
\end{tabular}

\begin{tabular}{|c|c|c|}
\hline 39 & 20 & 3.1 \\
\hline 40 & 17 & 2.6 \\
\hline 41 & 13 & 2.0 \\
\hline 42 & 14 & 2.2 \\
\hline 43 & 20 & 3.1 \\
\hline 44 & 13 & 2.0 \\
\hline 45 & 19 & 2.9 \\
\hline 46 & 35 & 5.4 \\
\hline 48 & 16 & 2.5 \\
\hline 49 & 28 & 4.3 \\
\hline 50 & 29 & 4.5 \\
\hline 51 & 28 & 4.3 \\
\hline 52 & 26 & 4.0 \\
\hline 53 & 18 & 2.8 \\
\hline 54 & 21 & 3.2 \\
\hline 55 & 25 & 3.9 \\
\hline 56 & 29 & 4.5 \\
\hline 57 & 29 & 4.5 \\
\hline 58 & 15 & 2.3 \\
\hline 59 & 18 & 2.8 \\
\hline 60 & 20 & 3.1 \\
\hline 61 & 19 & 2.9 \\
\hline 62 & 14 & 2.2 \\
\hline 63 & 10 & 1.5 \\
\hline 64 & 12 & 1.9 \\
\hline 65 & 9 & 1.4 \\
\hline
\end{tabular}




\begin{tabular}{lll}
\hline $\mathbf{6 6}$ & 2 & .3 \\
$\mathbf{6 7}$ & 6 & .9 \\
$\mathbf{6 8}$ & 5 & .8 \\
$\mathbf{6 9}$ & 2 & .3 \\
$\mathbf{7 0}$ & 3 & .5 \\
$\mathbf{7 1}$ & 1 & .2 \\
\hline
\end{tabular}

\begin{tabular}{ccc}
\hline $\mathbf{7 2}$ & 1 & .2 \\
73 & 3 & .5 \\
$\mathbf{7 4}$ & 1 & .2 \\
75 & 2 & .3 \\
$\mathbf{7 7}$ & 1 & .2 \\
Total & $\mathbf{6 4 8}$ & $\mathbf{1 0 0 . 0}$ \\
\hline
\end{tabular}

Table .2 shows the scores of candidate with the mode score of 50,56 and 57 , This indicates that majority of the candidates scored between 50 and 57 .

Table 3 Descriptive Statistics of Candidates

\begin{tabular}{ccccc}
\hline $\begin{array}{c}\text { No of } \\
\text { Candidates }\end{array}$ & $\begin{array}{c}\text { Minimum } \\
\text { score }\end{array}$ & $\begin{array}{c}\text { Maximum } \\
\text { Score }\end{array}$ & $\begin{array}{c}\text { Mean } \\
\text { Score }\end{array}$ & Standard Deviation \\
\hline 648 & 9 & 77 & 49.38 & 10.78 \\
\hline
\end{tabular}

Table 3 shows the mean score of candidate as 49.38 with the standard deviation of 10.78 . It also indicates the minimum score of candidate to be 9 and maximum score of candidate to be 77 . Using the above result to calculate the norm-reference method of standard-setting we have mean score minus $1 \mathrm{SD}$. That is 49-10 $=38.6$ approximately 39. The Angolf modified method reached for the cut-off point according to the University Admission Committee was 50.

\section{FINDINGS}

Research Question 1: What is the agreement between the two standards when used to analyse the candidate scores in Post UTME?

Table 4: Passing Scores and Rates for the two Methods

\begin{tabular}{lcc}
\hline Parameter & Angolf Method & Norm Reference Method \\
\hline Passing Score & 50 & 39 \\
Passing Rate & $54 \%$ & $85 \%$ \\
Percentage Agreement & & $5 \%$ \\
\hline
\end{tabular}

Table 4 revealed that passing rate for Angolf modified to $54 \%$ whilst the Norm-reference method was $85 \%$. It also indicates the percentage agreement of the two methods to be $5 \%$.

Research question 2: What is the pass rates resulting from the application of the two standard setting methods on candidate scores in Post -UTME? 
Table 5: Percentage of Candidates that Passed and Failed the Post-UTME

\begin{tabular}{lcc}
\hline Methods & Pass Rate & Fail Rate \\
\hline Angolf Modified & $54 \%$ & $46 \%$ \\
Norm-reference & $85 \%$ & $15 \%$ \\
\hline
\end{tabular}

Table 5 under the Angolf modified method revealed that the percentage of candidates that passed the Post-UTME was 54\% and 46\% failed the examination. Also, under the Norm-reference, the percentage of candidates that passed the Post-UTME was $85 \%$ and $15 \%$ failed the examination.

\section{RESULT, DISCUSSION, AND SUGGESTIONS}

The results of the study revealed that there was very little agreement between the two methods used to determine the cut-off point. The pass rate was found to be $54 \%$ with the Angolf modified method, whilst by the norm-reference method was $85 \%$. Thus, these two different standard of settings yielded different standards and the percentage agreement between the two methods was $5 \%$. İt shows that the best method of setting cut-off point was the Angolf method. This finding is similar to the reported study (Elfaki and Salih, 2015) when two methods of standard-setting in a medical students MQC exam in internal medicine were compared and found them to be significantly different with failure rates of $61 \%$ and $12 \%$ respectively.

Also, Verhoeven, et al (2002) compared the pass/fail rates derived from the modified Angolf method and norm-reference method (mean minus $1 \mathrm{SD}$ ) and found them to be significantly different with failure rates of $56.5 \%$ and $10.1 \%$ respectively. However, it has been fairly well established that different standard setting methods result in different cut-off points or passing scores, they can be made credible, defensible and acceptable by ensuring the credibility of judges and using a systematic approach. to collect their judgments (Downing,Tekian and Yudikwowsky 2006). Similarly, researchers who had worked on methods of standard settings have not agreed on the most appropriate number of judges, but they all agreed that larger numbers of judges might yield more valid and reliable results.

The findings of this study made the researcher to conclude that percentage agreement of the pass rates by the two methods is very low and this means that the methods are significantly different. Also the research support and recommend the use of Angolf modified method to determine Post-UTME cut-off points by the Universities.

\section{REFERENCES}

Ado, A.B (2015). Analysis of UTME and Post-UTME scores of Education students at Northwest University

Kano-Nigeria. Paper delivered at a Conference: 1st International Conference On Education, Beijing China , At Beijing China

Amatareotubo, M. (2006). Post-UME screening: Matters arising. Posted to the Web: 8/30/2006

Angoff WA. (1971). Educational Measurement. Washington DC:American Council on Education;.

Elfaki, O.M and Salih K,M,A (2015). Comparison of Two Standard Setting Methods in a Medical Students MCQ Exam in Internal Medicine. American Journal of Medicine and Medical. 5(4): 167 DOI; 10.5923i).ajmms.20150504.04

Kane M. (2003). Validating the performance standards associated with passing scores. Rev Educ Res.,64:42561. doi: $10.2307 / 1170678$.

Norcini J.J. (2003). Setting standards on educational tests. Medical Education,37:464-469. doi: 10.1046/j.13652923. 01495.x. 
Boursicot K, Roberts T. (2006). Setting standards in a professional higher education course: Defining the concept of the minimally competent student in performance based assessment at the level of graduation from medical school. Higher Education Quarterly,60:74-90. doi: 10.1111/j.1468-2273. 00308.x.

Case SM, Swanson DB. (1998).Constructing written test questions for the basic and clinical sciences. Philadelphia: National Board of Medical Examiners;.

Cusimano M. (1996). Standard-setting in medical education. Acad Med.;71:112-120. doi: 10.1097/00001888199610000-00062.

Downing SM, Tekian A, Yudkowsky R. (2006). Procedures foe establishing defensible absolute passing scores on performance examinations in health professions education. Teaching ' and Learning in Medicine;;18:50-57. doi: 10.1207/s15328015tlm1801_11.

Kilminster S, Roberts T.(2004) Standard setting for OSCEs: Trial of borderline approach. Advances in Health Sciences Education. 2004;9:201-209. doi: 10.1023/B:AHSE.0000038208.06099.9a.

Impara JC. (1997).Setting standards using Angoff's method: Does the method meet the standard? Invited address to Division D of the Midwestern Educational Research Association, Chicago.

Impara JC, Plake BS. (1998).Teachers' ability to estimate item difficulty: A test of the assumptions in the Angoff standard setting method. Journal of Educational Measurement, 35:69-81. doi: 10.1111/j.17453984.1998.tb00528.x.

Isaac O.B.(2010). Post-UME Screening Examination in Nigerian Universities: The University of Education, IkereEkiti (Tunedik) Experience. Library Philosophy and Practise

National Research Council (1999). Setting reasonable and useful performance standards. In: Pelligrino JW, Jones LR, Mitchellw KJ, editor. Grading the Nation's report card: Evaluating NAEP and transforming the assessment of educational progress. Washington, DC: National Academy Press; pp. 164-184.

Olayemi, I. K. \&Oyelekan, O. S (2009). Analysis of Matriculation and Post-Matriculation Examination Scores of Biological Science Students of Federal University of Technology, Minna Nigeria.Ilorin Journal of Education, 28 pp.11-18

Oyedele, A. (2008). Post-UME should not be scrapped-UNAD VC. The Punch (December 30): 41.

Searle J. (2000). Defining competency-the role of standard setting. Medical Education.;34:363- 366. doi: 10.1046/j.1365-2923.2000.00690.x.

Talente G, Haist SA, Wilson JF. (2003). A model for setting performance standards for standardised patient examinations. Evaluation and the Health Professions, 26:427-446. doi: 10.1177/0163278703258105.

Ume, T. A. (1979). "Centralization of University Co-ordination in Nigeria. Environmental Analysis". African Journal of Educational Research, 2(2), 41-56. Busa

Verhoeven BH, Van der Steeg AFW, Scherpbier AJJA, Muijtjens AMM, Verwijnen GM, van der Vleuten CPM. (1999). Reliabilty and credibility of an Angoff standard setting procedure in progress testing using recent graduates as judges. Medical education, 33:832-837. doi: 10.1046/j.1365-2923.1999.00487.x. 
Verhoeven BH, Verwijnen GM, Muijtjens AMM, Scherpbier AJJA, van der Vleuten CPM. (2002).Panel expertise for an Angoff standard setting procedure in progress testing: item writers compared to recently graduated students. Medical Education, 36:860-867. doi: 10.1046/j.1365-2923.2002.01301.x. 